\title{
URINARY CHOLESTEROL IN CANCER SCREENING
}

DIETER JÜNGST, M.D.

MARGARETE OSTERHOLZER, M.D.

ROLAND TAUBER, M.D.

HANS JOSEF KARL, M.D.

From the Departments of Medicine 2 and Urology,

Klinikum Grosshadern University of Munich, F.R. Germany

\begin{abstract}
Cholesterol determinations in morning urine samples were taken in 235 selected patients with a positive test for microscopic hematuria. Values ranged from 0.2 to $76.0 \mathrm{mg}$ (median 5.5) in 23 patients with urologic malignancies and from 0.1 to $33.4 \mathrm{mg}$ (median 1.1) in 38 patients with various benign diseases of the kidney or urogenital tract. In the 28 patients with urinary tract infections and 146 subjects without evidence of disorders of the kidney and the urogenital system, urinary cholesterol excretion was usually normal (0.1 to $1.9 \mathrm{mg}$; median 0.35). Using $1.0 \mathrm{mg}$ urinary cholesterol per morning urine as a cutoff point, sensitivity for urologic carcinomas is about 80 per cent with a comparable high specificity of 90 per cent. Therefore, subsequent measurements of urinary cholesterol in populations with microscopic hematuria could define two groups, one with high prevalence and one with low prevalence of urologic malignancies. The less complicated colorimetric instead of gas-liquid chromatographic determination of urinary cholesterol can be recommended as a screening test for urologic carcinomas in populations with microscopic hematuria.
\end{abstract}

Since the event of the polarizing microscope, birefringent or anisotropic crystals are well recognized components in the urinary sediment of patients with a variety of diseases, especially the nephrotic syndrome. ${ }^{1-3}$ This anisotopic material is apparently composed largely of cholesterol esters with a smaller proportion of free cholesterol. ${ }^{4}$ However, the quantitative determination of cholesterol in urine has received comparatively little attention. Reports in the literature ${ }^{5-16}$ have indicated that patients with benign and malignant diseases of the kidney or the urogenital tract frequently have marked elevations of cholesterol in their urine. Based on these studies it was suggested that the determination of urinary cholesterol may be of possible value in the diagnosis of urogenital carcinomas, especially of the prostate, kidney, and bladder.

The objective of a recent study was to determine whether or not this method could be used as a screening test in large numbers of patients. ${ }^{17}$
A high predictive value $(0.23)$ of a positive urinary cholesterol test result (exceeding the upper 3 SD limit) and the presence of urologic neoplasms in males was apparently due to patient selection. Therefore, because of the low prevalence of urologic carcinomas in an average population, this method has not been recommended as a primary screening test.

The present study was carried out to investigate the possibility of whether urinary cholesterol determinations could be successfully applied in preselected populations with an increased prevalence of urologic carcinomas due to a positive test result for microscopic hematuria.

\section{Material and Methods}

The study included a total of 235 patients, 119 males with an age range of fifty to eighty-two years (median 63.4) and 116 females with an age range of fifty to scventy-nine years (median 58.6). Criteria for selection were an age above 
TABLE I. Urinary cholesterol in patients with urologic carcinomas and microscopic hematuria

\begin{tabular}{clc}
\hline Diagnosis & $\begin{array}{c}\text { Tumor } \\
\text { Stage/Grade }\end{array}$ & $\begin{array}{c}\text { Cholesterol }(\mathrm{Mg}) / \\
\text { Morning Urine }\end{array}$ \\
\hline Carcinoma of & $\mathrm{T}_{1} \mathrm{~N}_{0} \mathrm{M}_{0} \mathrm{G}_{1}$ & 13.1 \\
bladder & $\mathrm{T}_{2} \mathrm{~N}_{0} \mathrm{M}_{0} \mathrm{G}_{2}$ & 11.1 \\
& $\mathrm{~T}_{1} \mathrm{~N}_{0} \mathrm{M}_{0} \mathrm{G}_{1}$ & 8.6 \\
& $\mathrm{~T}_{1} \mathrm{~N}_{0} \mathrm{M}_{0} \mathrm{G}_{1}$ & 6.3 \\
& $\mathrm{~T}_{1} \mathrm{~N}_{0} \mathrm{M}_{0} \mathrm{G}_{1}$ & 6.3 \\
& $\mathrm{~T}_{2} \mathrm{~N}_{0} \mathrm{M}_{0} \mathrm{G}_{2-3}$ & 4.3 \\
& $\mathrm{~T}_{3} \mathrm{~N}_{1} \mathrm{M}_{0} \mathrm{G}_{2}$ & 1.4 \\
& $\mathrm{~T}_{1} \mathrm{~N}_{0} \mathrm{M}_{0} \mathrm{G}_{0}$ & 1.2 \\
& $\mathrm{~T}_{3} \mathrm{~N}_{1} \mathrm{M}_{1} \mathrm{G}_{3}$ & 12.3 \\
& $\mathrm{~T}_{3-4} \mathrm{~N}_{2} \mathrm{M}_{\mathrm{X}}$ & 1.3 \\
& $\mathrm{~T}_{2} \mathrm{~N}_{1} \mathrm{M}_{\mathrm{X}} \mathrm{G}_{2}$ & 0.7 \\
& $\mathrm{~T}_{2} \mathrm{~N}_{1} \mathrm{M}_{1} \mathrm{G}_{2-3}$ & 0.8 \\
Carcinoma of & $\mathrm{T}_{2-3} \mathrm{~N}_{0} \mathrm{M}_{0} \mathrm{G}_{3}$ & 0.4 \\
prostate & $\mathrm{T}_{2} \mathrm{~N}_{0} \mathrm{M}_{0} \mathrm{G}_{1}$ & 14.2 \\
& $\mathrm{~T}_{1} \mathrm{~N}_{0} \mathrm{M}_{0} \mathrm{G}_{2}$ & 76.0 \\
& $\mathrm{~T}_{2} \mathrm{~N}_{0} \mathrm{M}_{0} \mathrm{G}_{1}$ & 2.4 \\
& $\mathrm{~T}_{2} \mathrm{~N}_{1} \mathrm{M}_{\mathrm{X}} \mathrm{G}_{3}$ & 0.2 \\
& $\mathrm{~T}_{3} \mathrm{~N}_{1} \mathrm{M}_{\mathrm{X}} \mathrm{G}_{2}$ & 5.7 \\
& $\mathrm{~T}_{2} \mathrm{~N}_{0} \mathrm{M}_{0} \mathrm{G}_{1}$ & 8.8 \\
Carcinoma of & $\mathrm{T}_{2} \mathrm{~N}_{0} \mathrm{M}_{0}$ & 52.3 \\
kidney & $\mathrm{T}_{3} \mathrm{~N}_{1} \mathrm{M}_{1 \mathrm{~d}}$ & 2.8 \\
& $\mathrm{~T}_{1} \mathrm{~N}_{0} \mathrm{M}_{0}$ & 0.9 \\
& $\mathrm{~T}_{2} \mathrm{~N}_{1} \mathrm{M}_{\mathrm{X}}$ & 5.5 \\
\hline & & \\
& & \\
& &
\end{tabular}

fifty years and a positive test result for microscopic hematuria in the urinary sediment. These data were provided by the central institute of clinical chemistry and read from computer charts. The diagnoses of the investigated patients were usually not known at the date of the urinary cholesterol analyses which were performed exclusively on morning urine samples. Patients with urethral catheters, suprapubic fistula, or macroscopic hematuria were excluded from the study.

\section{Analysis of urinary cholesterol}

Urinary cholesterol was analyzed in 2 by $1-\mathrm{ml}$ aliquots of morning urine samples and expressed as $\mathrm{mg}$ cholesterol/sample considering the total volume. After extraction with $8 \mathrm{ml}$ chloroform/ methanol(3:1) and centrifugation, $5.0 \mathrm{ml}$ chloroform were removed and dried under a stream of nitrogen.

The residue was hydrolyzed with $0.5 \mathrm{ml}$ ethanolic $0.5 \mathrm{~N} \mathrm{KOH}$ at $60^{\circ} \mathrm{C}$ for sixty minutes and reextracted with $6 \mathrm{ml} \mathrm{n}$-hexane. A total of 5 $\mathrm{ml}$ extract was used for subsequent gas-liquid chromatography. The dried residue was dissolved in $0.1 \mathrm{ml}$ of the internal standard solution (10 mg 4-androstenedione/dl iso-octane). Two to
$3 \mu \mathrm{l}$ were injected on a $1.80 \mathrm{~m}, 1 \%-\mathrm{XE}-60 \mathrm{col}$ umn, i.d. $2 \mathrm{~mm}$, temp. const. $220^{\circ} \mathrm{C}$, and measured by flame ionization detectors.

Quantitation was performed due to the peak height ratio, since alterations of cholesterol/4androstenedione concentrations gave a linear response. The specificity of the method was confirmed by simultaneous mass-fragmentometric analysis in selected samples. Using this method an intra-assay variance of 5.6 per cent and an inter-assay variance of 10.4 per cent was calculated with an average recovery exceeding 90 per cent. A less complicated colorimetric determination of cholesterol in the dried hexane extracts is possible but was not used in this study.

\section{Results}

After completing the urinary cholesterol analysis, the evaluation of the clinical records revealed the presence of known urologic malignancies in 23 of 235 selected patients with a prevalence of 15.9 per cent in males and 3.4 per cent in females. Data on these patients including tumor stage and grade and the results of urinary cholesterol determinations are illustrated in Table I. In 38 patients various benign diseases of the kidney and the urogenital tract were present, and in 28 patients infections of the bladder had been diagnosed. In 146 patients with microscopic hematuria, clinical records revealed no evidence of diseases of the urogenital system. They consisted of 34 with endocrine and metabolic disorders, 43 with cardiovascular, 41

TABLE II. Urinary cholesterol in patients with benign diseases of kidney and urogenital tract or other internal disorders and microscopic hematuria

\begin{tabular}{|c|c|c|c|}
\hline \multirow[b]{2}{*}{ Diagnosis } & \multirow[b]{2}{*}{$\mathbf{n}$} & \multicolumn{2}{|c|}{$\begin{array}{l}\text { Cholesterol }(\mathrm{Mg}) / \\
\text { Morning Urine }\end{array}$} \\
\hline & & Range & Median \\
\hline Adenoma of kidney & 1 & 1.8 & 1.8 \\
\hline Adenoma of prostate & 3 & $0.2-4.4$ & 2.3 \\
\hline Urolithiasis & 12 & $0.1-9.6$ & 1.1 \\
\hline $\begin{array}{r}\text { Renal insufficiency } \\
\text { (cause unknown) }\end{array}$ & 5 & $0.2-7.2$ & 0.9 \\
\hline Nephrotic syndrome & 4 & $0.3-33.4$ & 4.2 \\
\hline Renal cyst & 3 & $0.1-10.4$ & 0.8 \\
\hline $\begin{array}{l}\text { Glomerular, tubular } \\
\text { and vascular dis- } \\
\text { eases of kidney }\end{array}$ & 10 & $0.2-4.4$ & 0.6 \\
\hline Infections of bladder & 28 & $0.1-1.7$ & 0.4 \\
\hline $\begin{array}{l}\text { Other internal } \\
\text { discases }\end{array}$ & 146 & $0.1-1.9$ & 0.3 \\
\hline
\end{tabular}


with gastrointestinal, 15 with respiratory, and 13 with hematopoietic diseases. The ranges and medians of the urinary cholesterol determinations in several groups of thesc patients are presented in Table II.

The correlation of sensitivity and specificity for urologic carcinomas at various cutoff points from 0.1 to $5.0 \mathrm{mg}$ cholesterol in morning urine is given in Figure 1.

\section{Comment}

Hyperexcretion of urinary cholesterol in association with urologic malignancies has been observed in several studies and was thought to be of value in the diagnosis of these diseases. ${ }^{5-16}$ In a prior study, positive test results, using the upper 3 SD limit as cutoff point, have been obtained in 13 of 430 male patients and in 9 of 545 female patients above fifty years old. ${ }^{17}$ There was no evidence of neoplasias or diseases of the kidneys and urogenital tract at the date of the urinary cholesterol analysis.

After further investigation, 2 carcinomas of the bladder and 1 carcinoma of the kidney were diagnosed in the male group while in female patients no malignancies could be detected. In most cases, however, nonmalignant diseases of the kidney and the urogenital tract seemed to be responsible for the measured increments of urinary cholesterol. The high predictive value $(0.23)$ of a positive urinary cholesterol test result, and the presence of urologic neoplasms in the male group, was obviously due to patient selection, since comparable results could not be expected in a normal population as well as in cancer screening.

Urinary testing for occult blood, usually by microscopic analysis, is a simple method which will result in an increased prevalence of urologic carcinomas in the average population. This method has a diagnostic sensitivity of about 45 to 70 per cent for these malignancies and increases the low prevalence from about 0.1 to 1 to 2 per cent in males and from $0.02-0.03$ to $0.2-0.3$ per cent in females above forty years old. The low predictive value of a positive test for occult blood $(0.002-0.02)$ and the presence of urologic malignancies clearly diminish the value of this method as an effective screening test.

The presented results demonstrated that subsequent measurements of urinary cholesterol in populations with microscopic hematuria could be advantageous in defining high-risk and low-risk groups for urologic carcinomas. For the given problem, the most practical cutoff value for the

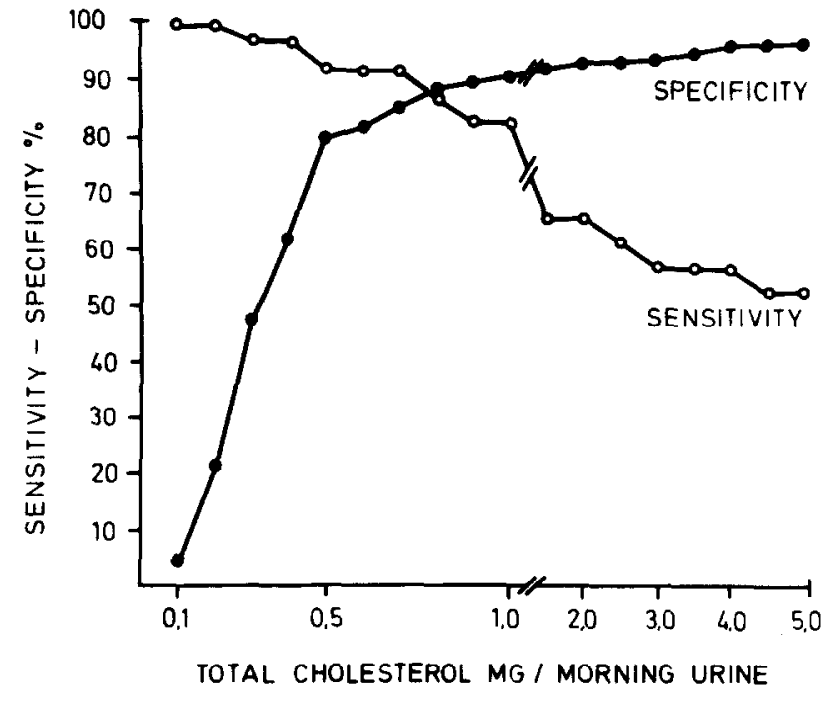

FIGURE 1. Correlation of sensitivity and specificity of cholesterol in morning urine for urologic carcinomas in population with microscopic hematuria.

urinary cholesterol method is $1.0 \mathrm{mg} / \mathrm{morning}$ urine. At this cutoff point, sensitivity for carcinomas of prostate, kidney, or bladder with associated microscopic hematuria is about 80 per cent with a comparable high specificity of $90 \mathrm{pcr}$ cent. Therefore, subsequent measurements of urinary cholesterol in populations with microscopic hematuria, which could be revealed in cancer screening, would increase the prevalence of urologic carcinomas in positive cases (exceeding $1 \mathrm{mg}$ cholesterol/morning urine sample) about eightfold.

The less expensive and complicated enzymatic assay of urinary cholesterol in the dried hexane extracts can be recommended as a secondary screening test for urologic carcinomas in selected populations with microscopic hematuria.

Marchioninistr. 15

8 München 70, F.R. Germany

(DR. JÜNGST)

ACKNOWLEDGMENT. Massfragmentometric analyses were provided by Dr. Jacob, Institute of Clinical Chemistry, Klinikum Grosshadern, University of Munich.

\section{References}

1. Comings DE: Anisotropic lipids and urinary cholesterol excretion, JAMA 183: 128 (1963).

2. Klahr S, Tripathy K, and Bolanos O: Qualitative and quantitative analysis of urinary lipids in the nephrotic syndrome, J Clin Invest 16: 1475 (1967).

3. Neumann $M$, West $M$, and Zimmermann $H$ : The relationship between proteinuria and fatty elements in the urine sediment, Am J Med Sci 241: 617 (1961).

4. Zimmer JG, Dewey R, Waterhouse C, and Terry R: The 
origin and nature of anisotropic urinary lipids in the nephrotic syndrome, Ann Intern Med 54: 205 (1961).

5. Acevedo HF, et al: Urinary cholesterol. V. Its excretion in men with testicular and prostatic neoplasms, Cancer 32: 196 (1973).

6. Belis JA, and Cenedella RJ: Urinary nonesterified cholesterol excretion in adenocarcinoma of the prostate, ibid 43: 1840 (1979).

7. Chu TM, Shukla SK, Mittelman A, and Murphy GP: Comparative evaluation of serum acid phosphatase, urinary cholesterol and androgens in diagnosis of prostatic cancer, Urology 6: 291 (1975).

8. Jüngst $\mathrm{D}$, et al: Urinary cholesterol excretion in men with benign prostatic hyperplasia and carcinoma of the prostate, Cancer 43: 361 (1979).

9. Jüngst $\mathrm{D}$, et al: Comparative evaluation of nonesterified and total urinary cholesterol in papilloma and carcinoma of the bladder ibid 43: 2486 (1979).

10. Jüngst $\mathrm{D}$, et al: Studies on the clinical significance of nonesterified and total cholesterol in urine, Klin Wschr 59: 545 (1981).
11. Bloch $\mathrm{E}$, and Sobotka $\mathrm{H}$ : Urinary cholesterol in cancer, J Biol Chem 124: 567 (1938).

12. Bruger $\mathbf{M}$, and Ehrlich SB: Cholesterol content of the urine in patients with cancer, Arch Intern Med 72: 108 (1943).

13. Burchell MM. Earle JHO, and Maclagan NF: Urinary cholesterol in cancer: urinary cholesterol excretion in cancer patients and control subjects, Br J Cancer 3: 42 (1949).

14. Frick J, and Spiteller G: Cholesterin und Harntrakterkrankungen, Z Urol 61: 833 (1968).

15. Trappe W: Über den Cholesteringehalt des Harns von Geschwulstkranken, Z Krebsforsch 53: 47 (1942).

16. Spiteller-Friedmann M, Spiteller G, Spiteller $\mathbf{H}$, and Frick J: Zur Frage der Ausscheidung von Cholesterin im Harn bei verschiedenen Erkrankungen (vornehmlich bei Tumorerkrankungen des Urogenitaltrakts), Ổterr Z Krebsforsch 5: 25 (1971).

17. Jüngst $D$, Tauber $R$, Osterholzer $M$, and Karl HJ: Is urinary cholesterol determination a possible screening test for urological carcinomas? Urol Res 9: 1 (1981). 